\title{
Synthesis and properties of microlanininate structures by ion beam assisted deposition
}

\author{
G.S. Was, J.W. Jones, C.E. Kalnas, L.J. Parfitt and A. Mashayekhi \\ The Unic ersity of Michigan, Ann Arbor, Mi 48109 , USA \\ D.W. Hoffman \\ Research Staff, Ford Motor Company, Destrom, MI 48I24, USA
}

\begin{abstract}
Films of $\mathrm{Al}, \mathrm{Al}_{2} \mathrm{O}_{3}$, Mo and $\mathrm{MoSi}_{4}$ were formed by ion beam assisted deposstion (IBAD) at $R$ ratios hetween 0.0104 and 10.1 and film ihicknesses between 150 and $1100 \mathrm{~nm}$. Al films were crystalline with a strong (111) fiber texture becoming more pronounced and azimuthally oriented with increasing $R$ ratio. Mo films were crystalline with strong (110) texture and a distinct azimuthal i. 5 tre indicative of planar channeling of the ion beam along (110) planes. The microstructure of $\mathrm{Al}$ films is characterized hy large columnar grains at $R=0$ with breakup starting at $R=004$, while that of Mo tilms showed little chang z with increasing $R$ ratio. $\mathrm{Al}_{2} \mathrm{O}_{3}$ and $\mathrm{MoSi}_{x}$ films are amorphous under all deposition conditions. The average stress in oxide and silicide films is tensile at $R=0$ and becomes compressive with increased values of the normalized energy, saturating at $\sim 15 \mathrm{eV} /$ atom. The average stress in Mo films is tensile at $R=0$. increases to a maximum value of $0.63 \mathrm{GPa}$ and becomes compressive with increasing normalized energy.
\end{abstract}

\section{Introduction}

Microlaminates have received considerable attention in recent years because of the potential to tailor compesition, microstructure and interface propertics to shance strength, toughness and oxidation resistance. Substantial increases in strength, for example, hive been reported for $\mathrm{Al} / \mathrm{Al}_{2} \mathrm{O}_{3}[1]$ and $\mathrm{Cu} / \mathrm{Ni}$ [2] when layer thicknesses were less than $500 \mathrm{~nm}$. In higit temperature $\mathrm{MoSi}$,-based composites, alloying with $\mathrm{Nb}$ has been shown to significantly increase tougtıness [3], an inherent problem with silicides. While vapor deposition has traditionally been use 1 to produce microlaminates, it has been recognized that significan? improvement in properties of films can be achieved by ion beam assistud deposition (IBAD). IBAD has been shown to increate fi!m density, promote equiaxed grain formation and film/substrate adherence, and provide control over crystal texure and residual stress [4]. The objective of this rescalch is to synthesize $\mathrm{Al} / \mathrm{Al}_{2} \mathrm{O}_{3}$ and $\mathrm{Mo} / \mathrm{MoSi}_{2}$ microlaminates by IBAD with the intent of developing an understanding of the dependence of microstructural and geometric variables on strength and fracture resistance. The work reported here describes the synthesis and characterization of monolithic $\mathrm{Al}_{2} \mathrm{O}_{3}$, pure $\mathrm{Al}$ metal films and $\mathrm{Mo} / \mathrm{MoSi}_{\text {r }}$ microlaminates produced by ion heam assisted deposition.

\section{Experiment}

Ion beam assisted deposition was conducted in a chamber containing two $6 \mathrm{~kW}$ electron beam guns and a $3 \mathrm{~cm}$ Kaufman ion gun with a base pressure of $2 \times 10^{-1)}$ Torr for 200 and $1000 \mathrm{~nm}$ thick $\mathrm{Al}_{2} \mathrm{O}_{2}$ films

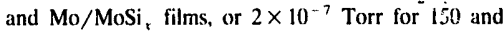
$400 \mathrm{~nm}$ th: ${ }^{2} \mathrm{~A}_{2}{ }_{2} \mathrm{O}_{3}$ films. Depositions were normal to the substrate at the following rates; $\mathrm{Al}: 0.7 \mathrm{~nm} / \mathrm{s}$, $\mathrm{Al}_{2} \mathrm{O}_{3}: 1.0 \mathrm{~nm} / \mathrm{s}$, Mo: $0.25 \mathrm{~nm} / \mathrm{s}$, and $\mathrm{MoSi}_{\mathrm{r}}: 0.25$ $\mathrm{nm} / \mathrm{s}$ for Mo and $0.65 \mathrm{~nm} / \mathrm{s}$ for Si. Ion bombardment was pciformed using 209 to $\$ 93 \mathrm{cV} \mathrm{Ar}^{+}$ions at an angle of $45^{\circ}$ to the substrate normal, with current densities in the range 2 to $190 \mu \mathrm{A} / \mathrm{cm}^{2}$, giving a range of $R$ (ion/atom arrival rate) ratios from 0.004 to 0.1 , table 1. Results are also expressed in terms of the normalized energy, $E_{n}$, which is the product of the beam voltage and the $R$ ratio. The chamber pressure during deposition was $1-3 \times 10^{-5}$ Torr. Deposition raiss for each source were measured independently with quartz crystal monitors and the beam current was monitored with a Faraday cup. Deposited films ranged in thickness from 150 to 1100 niì.

The amount of material deposited and the composition or stoichiometry of the films deposited onto graphite foil were determined by Rutherford backscattering analysis at an angle of $165^{\circ}$, and fit with the aid of the program. RUMP [5]. Crystallinity and texture 
Table 1

Deposttion parameters and composition analysis of 1,3AD films

\begin{tabular}{|c|c|c|c|c|c|c|c|}
\hline $\begin{array}{l}\text { Film } \\
\text { iype }\end{array}$ & $\begin{array}{l}\text { Nominal } \\
\text { thicknes [nm] }\end{array}$ & $\begin{array}{l}R \text { ratio } \\
\text { [on /atom] }\end{array}$ & $\begin{array}{l}\text { Energy } \\
\text { [eV/ion] }\end{array}$ & $\begin{array}{l}E_{\mathrm{n}} \\
{[\mathrm{cV} / \mathrm{atom}]}\end{array}$ & $\begin{array}{l}(\mathrm{O} / \mathrm{Al} \text { or } \mathrm{Mo} / \mathrm{SI} \\
( \pm 0.01)\end{array}$ & $\begin{array}{l}\text { Ar [at. } \%] \\
( \pm 0.02)\end{array}$ & $\begin{array}{l}O[a t . \%] \\
( \pm 0.1)\end{array}$ \\
\hline \multirow[t]{17}{*}{$\mathrm{Al}_{2} \mathrm{O}_{3}$} & \multirow[t]{6}{*}{$i 50$} & 0 & 0 & 0 & 1.61 & 0 & - \\
\hline & & 0.004 & 320 & 1.44 & 1.56 & 0.47 & - \\
\hline & & 0.01 & 281 & 2.81 & 1.52 & 0.47 & - \\
\hline & & 0.04 & $4(00)$ & $\operatorname{lt}, 0$ & i. .50 & 308 & - \\
\hline & & 01368 & 560 & 38.1 & 1.52 & 2.93 & - \\
\hline & & 0.1 & 587 & 58.7 & 1.47 & 4.03 & - \\
\hline & \multirow[t]{3}{*}{$2(0)$} & 0 & 0 & 0 & 1.67 & 0 & - \\
\hline & & 0.01 & $3 x t$ & 3.4 & 149 & 0.99 & - \\
\hline & & 0.1 & 593 & 59.3 & 1.47 & 4.12 & - \\
\hline & \multirow[t]{4}{*}{$4(M)$} & 0 & 0 & 0 & 167 & 0 & - \\
\hline & & 0.004 .5 & 320 & 1.44 & 1.53 & 0.65 & - \\
\hline & & 0.01 & $2 \times 1$ & 3.7 & 1.53 & 1.19 & - \\
\hline & & 0.04 & 400 & 16.0 & 1.50 & 2.96 & - \\
\hline & \multirow[t]{4}{*}{1000} & 0 & 0 & 0 & 1.33 & 0 & - \\
\hline & & 0.0104 & 209 & 0.84 & 1.41 & 0.62 & - \\
\hline & & 0.04 & 500 & 20.0 & 1.3 .3 & 0.5 & - \\
\hline & & 0.1 & 593 & 59.3 & 1.53 & 4.31 & -. \\
\hline \multirow[t]{4}{*}{ Al } & \multirow[t]{4}{*}{10001} & 0 & 0 & 0 & - & 0 & 6.1 \\
\hline & & 0.1014 & 250 & 1 & - & 0.47 & 3.8 \\
\hline & & 0.04 & 488 & 19.5 & - & 5.48 & 3.2 \\
\hline & & 0.1 & 463 & 46.3 & - & 417 & 3.1 \\
\hline \multirow[t]{6}{*}{ Mo } & \multirow[t]{6}{*}{$2(H)$} & 0 & 0 & 0 & - & . & 17.0 \\
\hline & & 0.01 & 251 & 2.5 & - & 8.69 & 12.2 \\
\hline & & 0.025 & .340 & 8.5 & - & 60 & 14.9 \\
\hline & & 0.05 & 376 & 18.8 & - & 0,7 & 9.0 \\
\hline & & 0.075 & 409 & 30.7 & - & 1.0 & 6.6 \\
\hline & & 0.10 & 461 & 46.1 & - & 1.0 & 5.1 \\
\hline \multirow[t]{6}{*}{ MoSi, } & \multirow[t]{6}{*}{200} & 0 & 0 & 0 & 1.35 & 0 & 3.8 \\
\hline & & 0.01 & 345 & 3.5 & 1.36 & 0.75 & 4.6 \\
\hline & & 0.025 & 415 & 10.4 & 1.37 & 1.43 & 3.8 \\
\hline & & 0.05 & 471 & 23.6 & 1.34 & 2.58 & 2.9 \\
\hline & & 0.1775 & 188 & 30.0 & 1.27 & 3.49 & 2.4 \\
\hline & & 0.10 & 516 & 51.6 & 1.21 & 4.94 & 2.4 \\
\hline
\end{tabular}

were determined by $X$-ray diffraction (XKL) using Cu $K_{\text {ar }}$ radiation in a Rigaku diffractometer sperated at $40 \mathrm{kV}$ and $100 \mathrm{~mA}, \theta / 2 \theta \mathrm{s}$.ans of rotating samples were conducted for buth $\mathrm{Al}$ is du $\mathrm{Al}_{2} \mathrm{O}_{3}$ films of thickness $1000 \mathrm{~nm}$. Pole figures were generated for the Al (111), (200) and (220) poles. $\theta / 2 \theta$ scans of rotating samples were conducted for Mo filnes of thickness 1000 $\mathrm{nm}$ and pole figures were generated for the $(110)$ pole. Grain size and morphology were determined from transmission electron microscopy (TEM) of planar and cross section samples on a JEOL 2000 FX TEMSCAN at $200 \mathrm{kV}$. Residual stress was determined by optical interferometry [6] on $150-400 \mathrm{~nm}$ films of $\mathrm{Al}_{2} \mathrm{O}_{3}, 200$ $\mathrm{nm}$ films of Mo and $\mathrm{MoSi}_{r}$, and a 50 vol $\% \mathrm{Mo} / \mathrm{MoSi}_{r}$ microlaminate deposited onto glass cover slips $(150 \mu \mathrm{m}$ thick). The curvature of the cover slip relative to an optical flat was determined before and after deposition hy observation in monouhromatic light. Curvatures were determined by lcas: squares finting of parabolas to the recorded fringe spacings and are related to the average stress in the film [6]. All calculations of stress were made using the nominal film thicknesses.

\section{Results and discussion}

\subsection{Coating composition and microstruciste}

In all the $\mathrm{Al}_{2} \mathrm{O}_{3}$ films except those at $1000 \mathrm{~nm}$, there is a decrease in the $\mathrm{O} / \mathrm{Al}$ stoichiometry with increasing $R$ ratio, consistent with observations reported by Shimizu [7] and Kclly [8] for $1 \mathrm{kcV} \mathrm{Ar}^{+}$ bombardment of $\mathrm{Al}_{2} \mathrm{O}_{3}$ which show a preferential loss of oxygen during bombardment. The oxygen content in 

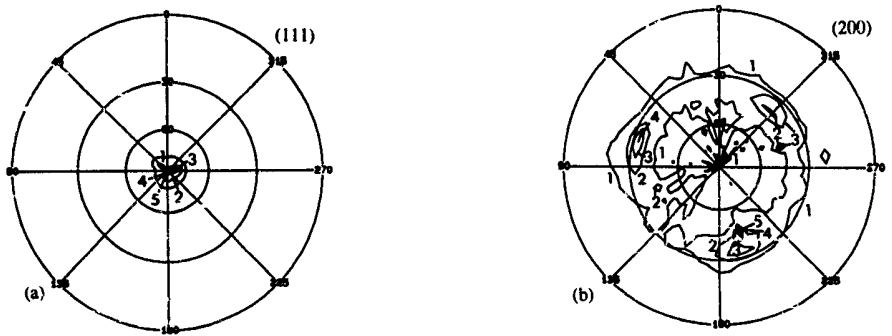

Fig. 1. (111) (a), and (200) (b) pole figures of $1 \mu \mathrm{m}$ thick Al deposited at $R=0.1$ (46 eV/atom) usmg $593 \mathrm{eV}^{+}$at $45^{\circ}$ to the substrate normal.

the $\mathrm{Al}$ films is relatively constant at about 3 at.\% in the films deposited during bombardment. This is about half the value of that incorporated without bombardment (F VD) and is consistent with results of Cuomo et al. [9] who found that ion bembardment of $\mathrm{Nb}$ during film growth restits in a "cleaning effect" in which the sputter yield ratio of $\mathrm{O}$ to $\mathrm{Nb}$ approaches 40 . Ar incorporation into boih $\mathrm{Al}_{2} \mathrm{O}_{3}$ and $\mathrm{Al}$ metal is a function of the $R$ ratio and reaches a value of about 4 at.\% at $R=0.1$.

In Mo films, there is a decrease in the oxygen content with increasing $K$ ratio from $i T$ at. $\%$ (ipivi a 5 at.\% $(R=0.1)$, in agreement with results of Cuomo et al. [9]. Ar entrapment remained low, amounting to only 1 at.\% at the highest $R$ ratio, also consistent with measurements on $\mathrm{Nb}$ [9]. The $\mathrm{Si} / \mathrm{Mo}$ ratio of the silicide ranged between 1.22 and 1.35 , considerably below the target value of 2.0 . This may be due to the shape of the Mo plume during deposition caused by uneven melting of the charge material. The $\mathrm{Si} / \mathrm{Mo}$ ratio decreased with increasing $R$ ratio indicating pref- erential sputtering of $\mathrm{Si}$, in agreement with results of Liau et al [:O\}] fer DtSi. The oxygen concentration remained low in $\mathrm{MoSi}_{x}$, and tended to decrease with increasing $R$ ratio. The Ar concentration was significantly higher in $\mathrm{MoSi}_{x}$ than in Mo metal which is consistent with observations of greater incorporation of Ar in amorphous ma:erials [11].

The FVD $(R=0)$ Al film displayed a strong (111) fibcr texture which was enhanced $w i t h$ ircreasing $R$ ratio, fig. 1a. The numbers on the polc figures refer to relative $X$-ray intensities. The $(200)$ pole figure of the rVD sample showed a strong azimuthal orientation, presumably influenced by the single crystal Si substrate. With increasing $R$ ratio, this azimuthal texture was gradually superseded in favor of a different azimuthal texture, fig. $1 \mathrm{~b}$, which is also consistent with planar channeling of the ions along (220) planes ((220) pole figure not shown). Recent observations of Dietz et al. [12] showed that a normalized energy of $80 \mathrm{eV} /$ atom is neecied to observe a channeling texture in $\mathrm{Al}$. The effect of ion Lombardment at lower values of $E_{\mathrm{n}}$ is
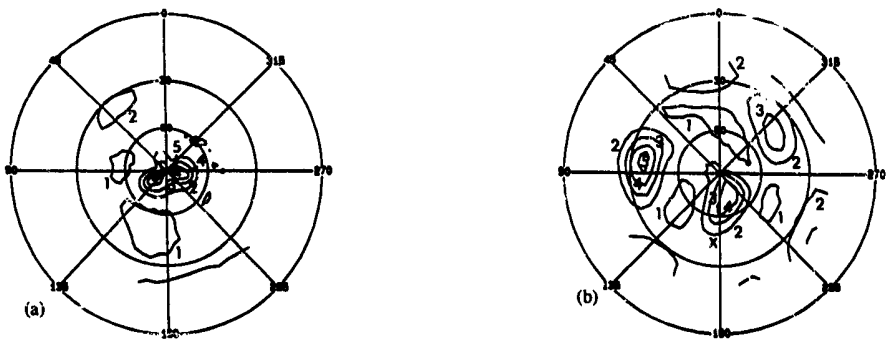

Fig. 2. (1 i0) pole figure of $t .1 \mu \mathrm{m}$ thick Mo films deposited at (a) $R=0$ (PVD), and (b) $R=0.1$ (46 eV/atom) 1 sing $500 \mathrm{eV} \mathrm{Ar}{ }^{+}$at $45^{\circ}$ to the substrate normal. 
primarily to increase atomic mobility, allowing more compietc development of the preferred growth texture. Their observations are generally consistent with ours except that we observed the development of a channeling tixture at $46 \mathrm{eV} /$ atom. Alumina and silicide films were amorphous over all $R$ ratios.

The (110) pole figure for the $1 \mu \mathrm{m}$, PVD Mo film, fig. 2a, showed a strong (110) fiber texture pernendicular to the film surface, consistent with the growth texture of bcc films [13]. The pole figure for the $1 \mu \mathrm{m}$, $R=0.1$ Mo film, fig. $2 \mathrm{~h}$, indicated a strong (110) fiber texture at an angle of $15^{\circ}$ to the substrate, as well as a distinct azimuthal texture represented by the areas of high intensity 60 radial degrees from the fiber axis. The evolution of the azimuthal texture is indicative of planar channcling of the ion beam along (iiv) plaies in the film, resulting in a preferred orientation of the grains along the ion bean direction [13,14]. This channeling behavior is indicated by the high intensity areas located $50^{\circ}$ to the ion beam direction. The tilt in the fiher axis is not weil understood but correlates ivith the beam direction.

TEM of planar and cross section samples revealed that the PVD Al films consist of columnar grains extending through the thickness of the sample (1000 nmi, fig. 3. Grain ulameters are $0.3-0.5$ times the length. The size of the grains inciicates that the tilm tempcrature during deposition was probably less than $200^{\circ} \mathrm{C}$ [15]. Ion bombardment with an $K$ ratio of 0.04 showed a predominantly columinar structure with a disnersion of fincr grains, principally at thi film-sub-
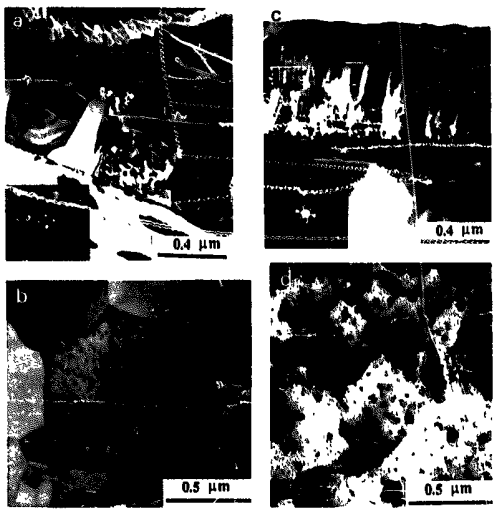

Fig. 3. Bright field electron micrographs (planar and cross section) of $\mathrm{I} \mu \mathrm{m}$ tíici Ai îins ior $R=0$ (PVD) $(\mathrm{a}, \mathrm{b})$, and $R=0.04$ using $488 \mathrm{eV} \mathrm{Ar}^{+}$(c, d).
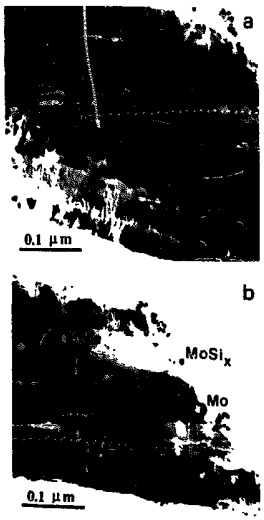

Fig. 4. Bright fieid electron micrographs of cross sections of $1.1 \mu \mathrm{m}$ thici $\mathrm{Mo} / \mathrm{MoSi}_{x}$ films (a) $R=0$ (PVD) and (b) $R=0.07$ for Mo layers and $R=0.01$ for $\mathrm{MoSi}_{x}$ layers.

straye interface, fig. 3. The grain size changes from about $0.5 \mu \mathrm{m}$ (PVD) tn $0.2 \mu \mathrm{m}(R=0.1)$. These results suggest that ion bombardment during deposition is increasing the nucleation density, and is most effective at the substrate-film interface.

Bright field transmission electi on micrographs from cross sections of $\mathrm{Mo} / \mathrm{MoSi}_{x}$ muttilayers deposited by PVD and IBAD are showin in fig. 4. The microstructure shows a fine grain thtructure for the Mo phase ( $<10$ nimi) and a tenturteless but "streaked" structure for the silicise phase. The streaking is most likely due to density variatious caused sither by cracking or the formation of voids. There is ittle difference between the PVD and IBAD micrestrictures except that in the IBAD microlaminate, the sireaking is less pronounced. These observations ars consistent with those of Harper et al. for $\mathrm{Nb}$ deposition [14].

\subsection{Residual stress}

Fig. 5 shows the variation of the average film stress for $\mathrm{Mo}, \mathrm{MoSi}_{x}$ and $50 \mathrm{vol} \% \mathrm{Mo} / \mathrm{MoSi}_{x}$ microlaminate as a function of the normalized energy $E_{n}$. The stress in the metal film starts out tensilc $(0.33 \mathrm{GPa}$ at $E_{\mathrm{n}}=0$ ), increases to a pcak of $0.63 \mathrm{GPa}$ at $E_{\mathrm{n}} \sim 9$ $\mathrm{eV} /$ atom. and becomes compressive at $E_{\mathrm{n}} \sim 30$ eV/atom. The stress of the PVD film $(R=0)$ is in agrcument in hoth sign and magnitude with Nh films deposited in a similar manner by Yee et al. [11]. Since the relative magnitudes of the coefficients of thermal expansion for Mo and the cover slip dictate a compres- 
sive stress, the measured tensile stress must be primarily intrinsic in nature. The initial rise in tensile stress and the stress reversal are consistent with the model by Müller [16] in which the rise in tensile stress is believed to be due to the removal of open porosity in the film resulting in is porous, but compact network in which the short range aitractive interatomic forces across sma!t defects can act most effectively. These results are also consistent with the idea of a critical film thickness at which the tensile stress increases abruptly due to interconncetion of the growing nuclei [17]. Further increases in $E_{\mathrm{n}}$ continue to density the film forcing the stress foward zero. The compressive stress at higher values of $E_{n}$ is probably duc to point defect production by irradiation damage. Although oxygen incorporation añ Ar entrapment have been suggested as possible causes for residual stress changes [18], neither is able to accosilt for the observed behavion of the Mo films.

The silicide and alumina films, figs. 5 an 16 , behave very differently from the metal itims ill that the stress decreases at a : sry low value of $E_{n}$, crosses into the compressive range varlier, and saturates by 15 $\mathrm{eV} /$ atom. The immediate decrease in :ucss and the lower crossover values of $E_{\mathrm{t}}$ may be rejated to the lower value of the activation energy for self-diffusion in an amorphous structure as compared to a crystalline lattice. Yce et al. [11] found that the $R$ ratio recuired to caus a transition from tensile to compressive stress was as much as a factor of $\mathbf{3}$ smaller for amorphous $\mathbf{W S i}$, than for crysialline $\mathrm{Nb}$. The saturation in the value of the compressive stress with increasing $R$ ratio is expected for an amorphous structure where the mechanism is duc to densifiestion of the microstructwie and not the introduction of lattice defects. The higher stom mobility in the amorphous structure may rcsult in more rapid densification causing the climination of the tensile stress peak, or an effective shift of the curve to lower values of $E_{n}$. An alternat'se expla-

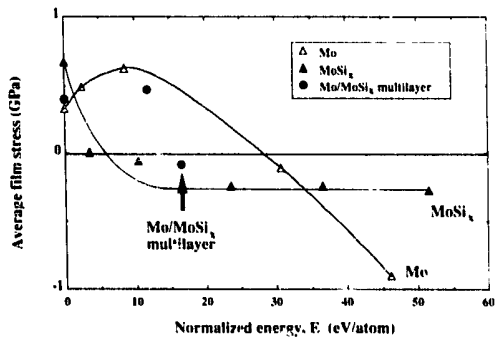

Fig. 5. Average filin stress as a function of the normalized

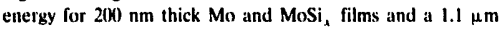
thich microlaminate of $\mathrm{Mo} / \mathrm{MoSi}_{r}$.

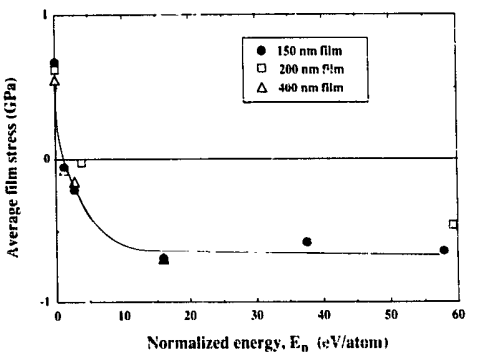

Fig. 6. Average film stress as a function of the normalized energy for $\mathrm{Al}_{2} \mathrm{O}_{3}$ samples of nominal thickness $150,2(0)$ and $400) \mathrm{nm}$.

nation tor the change in film stress is the entrapment af Ar The form of $\mathrm{Ar}$ in the film is not known, but if it were in solution, then a residual compressive stress would be expected. However, if Ar entrapment was responsible for the compressive stress, then the stress should continue to become more compressive with $E_{\mathrm{n}}$ rather than saturating as observed. Results for multilayer films consisting of five bilayers of $50 \mathrm{vol}\left(\mathrm{r}_{\mathrm{s}}\right.$ Mo and 50 vol $\% \mathrm{MoSi}$, are also shown in fig. 5. The point marked by the arrow designates a film synthesized using $R=0.07$ for the Mo layers and $R=0.01$ for the MoSi, iayers corrusponding to the crossover points for the pure constituents. Although the residual stresses in the ermposite the nes obey a ditcu superposition of the stresses of the individual layers, the same trend is evident.

\section{Conclusions}

Ion beam assisted deposition of $\mathrm{Al}, \mathrm{Al}_{2} \mathrm{O}_{3}, \mathrm{MC}$, and $\mathrm{MoSi}$, using 209-5.93 $\mathrm{cV} \mathrm{Ar}^{+}$ions was found to strongly affect the composition, microstructure, texture and residual stress.

- Increasing $R$ ratio lcads to an increase in Ar entrapment and a reduction in oxygen incorpor:tion in all films. In $\mathrm{Al}_{2} \mathrm{O}_{1}$ and $\mathrm{MoSi}$, films, the stoichiometry becomes increasingly tich in the metuitic specic due in preferential sputtering of the light element.

- The (111) fiber texture of reposited $\mathrm{Al}$ is intensified with ion bombardment and an azimuthal texturc induced by planar channeling along (220) planes develops at higher $R$ ratios. The (110) fiber texture of deposited Mo is intensified with ion bombardment and an azimuthal textare develops dew to planar channeling of the ion beam along $(110)$ planes in the film. 
- Ion bembardment during Jeposition results in a breakup of the columnar grain structure and a reduction in grain size in Al films, but produces little visible change in the Mo layers except for a decrease in contrast variations in the silicide layers, presumably due to densification.

- Residual stress in $\mathrm{A}_{2} \mathrm{O}_{3}, \mathrm{MoSi}_{\lambda}$ and Mo films, and a 50 vol $\% \mathrm{Mo} / \mathrm{MoSi}_{x}$ microlaminate changes from tension to compression with increasing normalized energy, probably due to ion beam induced densification of the film.

\section{Acknowiedgements}

The authors sincerely acknowledge The Michigan Ion Beam Laboratory for Surface Modification and Analysis for the use of the IBAD facilities and the Elcction Microbean Analysis Laboratory. This work was supported under NSF grant no. DMR-9100361 and visder the Air Force Office of Scientific Research, University Research Initiative Program, contract ro. DOD-G-AFOSR-90-0141, Dr. Alan H. Rosenstein, Program Director.

\section{References}

[1] A.T. Alpas, J.D. Embury, D.A. Hardwick and R.W. Springer, J. Mater. Sti. 25 (1990) 1603.
[2] D. Tench and J. White, Metall. Trans. 1.iA (1984) 2039.

[3] T.C. Lu, A.G. Evans, R.J. Hecht and R. Mehrabian, Acta Metall. 39 (1991) 1853.

[4] F.A. Smidt, Int. Mater. Rev. 35 (1990) 61

[5] L.R. Dolittle, Nucl. Instr. and Meth. B9 (i985) 334.

[6] J.A. Thornton, J. Tabock and D.W. Hoffman, Thin Solic Fiint 64 (i979) 1 ii.

[7] R. Shimizu, Nucl. Instr. and Meth. B18 (1987) 486.

[8] R. Kelly, ibid., p. 388.

[9] J.J. Cuomo, J.M.E. Harper, C.R. Guarnieri, D.S. Yee, L.J. Attanasio, J. Angilelio and C.T. Wu, J. Vitc. Sci. Technol. 20 (1982) 349.

[10] Z.L. Liau, J.W. Mayer, W.L. Brown and J.M. Poate, J. Appl. Phy, 49 (1978) 5295.

[11] D.S. Yee, J. Floro, D.J. Mikalsen, J.J. Cuomn, K.Y. Ahn, and D.A. Smith, J. Vac. Sci. Technol. A3 (1985) 2121.

[12] V. Dietz. P. Ehrhart, D. Guggi, H.-G. Haubold, W. Jager, M Prieler and W. Schilling, Surf. Coat. Technol. 43/44 (1990) 96.3.

(13] I.. See, I.M.E. Harper, J.J. Cuomo and D.A. Smith, J. Vac. Sci. Technol. A4 (1986) 443.

(14] J.M.E. Harper, D.A. Smith, L.S. Yu and J.J. Cuomo, in: Beam-Solid Interactions and Phase Transformations, eds. H. Kurz. G.L. Olsen and J.M. Poate, Mater. Res. Soc. Symp. Proc. 51 (1986) p. 343.

115] C.R.M. Grovenor, H.T.G. Yentzell and D.A. Smith, Acia. Metall. 32 (1984) 773.

[16] K.-H. Müller, J. Appl. Phys. 62 (1987) 1796.

[17] R.W. Hoffm.ın, in: Physics of Thin Films, eds. G. Hass and R.E. Tl un (Academic Picss, New York, 1966) p. 230.

[18] T. Wu, J. Vac. Sci. Technol. 20 (1982) 349. 